\title{
On The Role Of Accountability And Incentives In Obtaining Quality Process Documentation
}

Krishnamurthy Surysekar (Email: suryseka@fiu.edu), Florida International University Balasubramaniam Ramesh (Email: Bramesh@gsu.edu), Georgia State University

\begin{abstract}
The importance of managing process knowledge in complex activities such as information product development is well recognized in recent research. However, successful implementation of a traceability scheme(that provides the ability to follow the life of artifacts created during systems development) to manage process knowledge requires the development of appropriate incentives to knowledge workers. Based on a review of accounting and economic literature on managerial incentives and accountability as well as empirical studies of nearly thirty organizations, we propose a series of hypotheses that predict the influence of an organizational culture of accountability and presence of financial and other incentives on obtaining quality process documentation in organizations.
\end{abstract}

\subsection{Introduction}

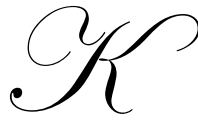

nowledge is increasingly being viewed as a key element of competitive advantage by firms. Knowledge based activities are increasingly becoming central functions of organizations [30] [9] whose very survival is often determined by their ability to manage knowledge work and knowledge assets that account for much of their productivity gains [8]. Productive knowledge workers are increasingly recognized as the most critical assets of the $21^{\text {st }}$ century organization [12]. In the knowledge economy, information products play a central role. An information product is defined as a highly interdependent package of information [13] that is capable of being distributed in digital form [34]. Software engineering products, CD-ROM databases, print-on-demand services, electronic libraries, electronic newspapers, and Web content are examples of such products [28] [33]. We view information product development as a knowledge intensive activity. The importance of capturing and reusing knowledge of development of information products, which we refer to as process knowledge, has been well recognized in recent research [35]. A central issue in implementing a comprehensive program for process knowledge management is the role of an organizational culture of accountability and the development of appropriate incentive schemes to provide motivation to knowledge workers involved in this activity [31].

\subsection{Information Product Development as a Knowledge Intensive Activity}

Development of information products is recognized as a knowledge intensive activity by many researchers [33] [39]. Further, products in the information industries have high levels of embedded knowledge content [27]. In successful information product development (IPD) firms, as a firm gains experience through the development of information products, much of the lessons learned remain captured as information [13] that is applied i.e. converted to knowledge [10]. As teams in an organization engage in the development of new products and services, the underlying rationale used to make decisions at various points in the design process need to be effectively captured and reused [37] to provide support for decisions in later projects or in the production of subsequent product versions. Therefore, it is critical to acquire and apply lessons learned and design decisions made in earlier projects in similar contexts. Effective management of knowledge associated with the design of their products and services helps organizations with purposeful opportunism

Readers with comments or questions are encouraged to contact the authors via email. 
in their offerings. This necessitates a closer examination of the role of knowledge in the design process, and mechanisms for supporting it.

\subsection{Role of Process Knowledge}

Drucker [11] argues that knowledge is productive only if it can be put to use by improving the processes or tasks that an organizations is engaged in. This requires systematic and organized application of knowledge to enhance, validate and apply existing knowledge [12]. Bohn [7] characterizes knowledge in business organizations along a processcapability continuum. In this scheme, the processes used by a 'mature' organization move up from a learning process to a systematic process that uses insights gained (say, from the development of previous versions of a product or service). Recent research in production management in publishing and design tasks points to this transition from a craft (identified by the first four of the eight stages in Bohn's [7] process knowledge framework) to process orientation (as characterized by stages 5 through 8 ). It should be noted that the movement along this continuum is very difficult [6] as it requires transition from a handicraft-based approach to product development to a process orientation. Use of the term "handicraft" emphasizes the high level of tacit knowledge in such processes. A large part of underlying process knowledge is held tacitly by knowledge workers [12]. Any attempt to support developmental activities of this nature, including design of information products, must account for and acknowledge tacit knowledge creation, use, and sharing by design. Lack of appropriate mechanisms to support process knowledge management may lead to a variety of problems including lack of shared understanding among development team members, loss of collaborative synergy due to team fluidity, repetition of mistakes and reinvention of solutions, versioning inconsistencies, inaccuracy of decisions or lack of shared goals stemming from unstated assumptions [35]. Recent research recognizes that tracking the history of design decisions can help alleviate these problems. Maintenance of comprehensive traceability ${ }^{1}$ can help avoid rework and help reuse lessons learned [35].

\subsection{Role of Incentives}

Our empirical studies on the factors influencing traceability practice highlight the importance of incentives to knowledge workers implementing traceability [32] [31]. The study included nearly thirty major system development organizations drawn from a wide variety of industries, including defense, government, aerospace, hardware development, pharmaceuticals, utility, system integration, electronics and telecommunications.

In this study, we observed that there are two extremes with respect to experience with requirements traceability, which we refer to as low-end and high-end traceability users ${ }^{2}$. Low-end users view traceability simply as a mandate from the project sponsors, whereas high-end users view traceability as an important component of a quality product development process.

The traceability practice of the two groups varies considerably. Low-end users use simple traceability schemes to model dependencies among requirements, allocation of requirements to system components and compliance verification procedures. Low-end users do not capture process-related traceability information such as rationale behind various artifacts and the evolution of these artifacts. High-end users employ much richer traceability schemes, thereby enabling more precise reasoning about traces and also use traceability information in much richer ways. They also emphasize the capture of process related traceability information.

An important observation from this study is that for a traceability scheme to be successful, it is necessary that appropriate incentives be provided to the individuals involved in the creation, maintenance and use of this information. Such incentives could either come in the form of direct incentives like bonuses for developing accurate process documentation, as well as an organizational culture where employees are held accountable for their actions. Schedule and cost constraints are primary reasons that inhibit traceability practice. Efforts towards maintaining comprehensive traceability are not adequately accounted for in measuring the productivity of individuals involved. In the absence of

1 Traceability is "the ability to describe and follow the life of an artifact, in both a forward and backward direction, i.e. from its origins, to its subsequent deployment and use, and through periods of on-going refinement and iteration".

2 It should be noted that any given organization may have a mix of high-end and low-end practices. 
adequate incentives, individuals tend to view traceability efforts as unnecessary "overhead" impeding their productivity. Further, if participants may perceive traceability as a mechanism to document their expertise, they may fear for their job security.

In this paper, we draw upon some significant theoretical work in the area of accounting and economics that has dealt with the use of incentives in an environment characterized by economic contracts and information asymmetry between contracting parties. Based on the results from this work, we develop some hypotheses on the use of appropriate incentives to facilitate traceability. We discuss the validity of the hypotheses using qualitative data obtained from our empirical study of traceability practice.

\subsection{The Economics of Managerial Incentives}

A significant body of theoretical and empirical research in economics and accounting shed light on the importance as well as limitations of economic incentives to motivate managers to act in the best interests of the firm. Two fundamental premises need to be stressed right away. First of all, managers' actions cannot be perfectly observed, but the outcomes of such actions can be. The implication of this premise is that there is no contract specifications that can say a manager gets a bonus for "working hard", but can specify a bonus for achieving a target level of growth in revenues or earnings. Whereas "working hard" is assumed to be positively correlated with achieving a positive growth in revenues or earnings, such outcomes are also a function of the environment. The manager may be better informed about this environment than the owners, but cannot control it. The second premise is that a manager acts in her or his own best interest, and does not necessarily gravitate to act in the best interest of the firm. There need to be a set of systems that align the interest of the managers with those of the firm. The question, therefore, is what kind of a contract would get the manager to do what is best for the shareholders, while guaranteeing that the manager would get at least what his opportunity costs of working for the firm. It is obviously not simple to design such a contract. On the one hand, a manager who is simply promised a share of the profits may be a risk-averse individual, not interested in risky compensation. On the other hand, a manager with a fixed guaranteed wage might not act to further profits. This line of research, the use of agency theory, has yielded very interesting insights into the use of performance indicators in managerial contracts, use of stock market performance versus accounting numbers in evaluating managers, the use of standards in managerial compensation, building of slack in budgets, and deliberately ignoring available information in performance evaluation. These are discussed briefly below.

Baiman [1,2] provides a comprehensive review of management accounting research involving the use of agency theory. Within the accounting field, management accounting is significantly concerned with performance evaluation, and, therefore, the role incentives have to play. Holmstrom [20] showed that, if there is a signal that has some information about the unobservable actions of an agent, it is economically optimal to include that signal in evaluating the manager's performance. Subsequent work by Baiman and Demski [3] and Holmstrom [21] extended the analysis further to challenge the long-held notion that a manager must be evaluated only based on factors that he controls. This is similar to rewarding a mutual fund manager based on not only the fund's performance, but also the performance of the fund relative to an index of similar funds. The reason is that there could be better information about the manager's unobservable actions when his performance is evaluated also on factors that he does not directly control. A number of researchers Baiman and Evans [4] and Balakrishnan et al [4] have focused on the nature of an information system that would be optimal in the presence of contracting frictions.

More recently, accounting and economics research has begun to look at situations when an agent has the potential to take more than one unobservable action. For instance, consider where an employee charged with implementing a software package is also required to document in sufficient detail how the implementation was arrived at. We may view the finished code as the product and the documentation as representing the process used in its development. The organization finds both useful. The process documentation is useful from an organizational learning point of view, for future similar work. However, from the point of view of client relations and competitive considerations, there may be pressure to produce the code on time. How does the organization design a suitable incentive mechanism that promotes both these actions? A key paper in this area is Holmstrom and Milgrom [21]. It considers the problem of unobservable allocations of agent efforts between multiple tasks, and provides a theoretical justification for the following: 
- Desirability of providing incentives for one activity decreases with the difficulty of measuring performance in any other activities that make competing demands o the agent's time and attention. For example, consider the earlier example of code writing. If the organization values a high quality documentation of the process, but finds it difficult to measure through a reliable signal, then it would not be optimal for the organization to provide incentives to the other more easily measured activity - i.e. producing the code on time. The intuition here from Holmstrom and Milgrom [21] is that, high-powered incentives for the easily measured activity will shift agent attention away from the other activity, and the firm would not benefit from this.

- $\quad$ Use of independent agents versus own sales personnel can also be explained in this fashion. One is likely to find the use of independent agents paid on a pay-for-performance basis when there are reliable signals to measure the effort of such agents. The presence of activities that are difficult to measure would promote the firms to use its own sales force, which may have less of its pay determined by incentive bonuses than outside sales forces.

- $\quad$ There is likely to be grouping of tasks based on precision of signals about the effort expended by agents on these tasks. Agents engaged in difficult to measure tasks may be paid a fixed salary, and agents engaged in easily measured tasks might be paid by high-powered incentives.

The grouping of tasks, the use of teamwork, and incentives associated with them have also been addressed in Hemmer [17].

Hemmer [18] considers a manager whose effort can be allocated between two activities. In this paper, it is shown that an incentive mechanism where added emphasis on one measure is accompanied by added emphasis on the other measure works under certain circumstances. Under other circumstances, the emphases on the two measures move in opposite directions.

Gibbons [15] provides an excellent critique of the prior theoretical work and proposes an integration of some organizational behavior paradigms. This paper summarizes recent research that does not follow the traditional agency theory paradigms, and makes the following additional suggestions:

- $\quad$ Use of subjective performance measures: The paper has an example of how Citicorp traders are evaluated partially based on their execution of trades to the satisfaction of the Citicorp sales force of the orders of their clients.

- $\quad$ Use of relational contracts that are influenced by subjective performance measures: Unlike the standard agency models, a relational contract is not subject to court enforcement. Technically, parties can renege on the contract. However, these contracts are enforced by the parties because of reputational reasons, and they contain sufficient incentives for the parties to not renege on them.

- Incentives to acquire skills: Here, the suggestion is to examine whether it is useful to evaluate an agent based on probable future contributions to the firm, as opposed to current contribution. While the firm incurs financial costs in the worker acquiring additional skills, the worker may give up some of his leisure time.

- $\quad$ Up-or-stay rules: The firm pays high wages for difficult jobs, and low wages for easy jobs. The key idea is that the wage differential is large enough so that the agent invests (at a private cost) to acquire the skills to do the difficult job. At the same time, the differential should also reflect the relative value of the respective tasks to the firm.

- $\quad$ Up-or-out rules: Here the contract specifies that the firm would either retain a worker after a probationary period by paying him a high wage, or fire him. In this case, there may be motivation by the workers to invest in skills when the job descriptions are not overly different. An example would be promotions of faculty members in universities.

It is also true that such interesting contracts may have their own problems with respect to enforcement. However, they are found in practice and may be worth considering in specific contexts.

There is also a rich body of empirical research grounded in the adoption of Total Quality Management (TQM) practices by firms. It would be impossible to review this body of literature extensively, and we provide a review of some 
key recent papers. Ittner and Larcker [22] [23] study the adoption of TQM plans by the firms and how their internal incentive systems are structured. They note an increased use of nonfinancial and operational measures like productivity and customer satisfaction in their internal systems for evaluating and rewarding managerial performance. Ittner, Larcker and Rajan [23] note increasing reliance on nonfinancial measures of performance in the compensation contracts of Chief Executive Officers (CEOs). Using time-series data, Banker, Potter, and Srinivasan [5], document a positive association between current nonfinancial performance measures and long-term financial measures for a chain of hotels.

\subsection{Organizational Culture of Accountability}

There is a significant body of accounting literature on the effect of accountability on decisions, particularly those made by auditors. In general, accountability has been defined as "the requirement to justify one's judgment to others" [25, p. 231]. In this experimental study, it is shown that tendency of an auditor to be more biased towards information obtained closer to a decision point than information obtained earlier can be reduced if the auditor is required to justify her/his decisions to a superior. Gibbins and Emby [14] point out that the ability to justify decisions is equivalent to greater documentation efforts. In an experimental study involving the performance of an ill-structured task, Kennedy et al [26] found that auditors were better able to justify their decisions with a consultation process, when provided with little authoritative guidance. When given more authoritative guidance, both the consulting process and the decision made affected their ability to justify their decisions. Turner [36], using an experimental study, reports that auditors who faced reviewers concerned about too much time being spent on items that were inconsistent with the client's explanations tended to follow a search that was prompted by the client. Hoffman and Patton [19] and Peecher [29] showed similar results in different task settings. Johnson and Kaplan [24] show that auditors who were told that their decisions would be subject to review and required justification worked towards greater consensus in the decisions, and had greater evidence of self-monitoring.

Thus, the review of accounting research into the important role of accountability in decision making leads to some interesting questions about what motivates employees to document their work accurately. First, if accountability is demanded, does that lead to better quality documentation? Second, in an environment of accountability, do team members achieve greater consensus on process documentation? Third, in the presence of greater accountability, are documentation efforts more geared to "pleasing the client"?

\subsection{Role of accountability and incentives in traceability practice: Hypotheses and observations}

Based on our analysis of the above literature on economic incentives and accountability, we propose several hypotheses in the following section. Qualitative data from our empirical studies support many of these hypotheses. Further, seemingly irrational behavior in traceability practice by some firms can be better understood by the hypotheses suggested by the literature. Obviously, our objective is not to prove or disprove the hypotheses in a positivistic sense, but to provide some pointers for future work to further the understanding of the role of accountability and incentives in process knowledge management.

H1A: When the quality of documentation cannot be measured accurately, firms either contract this activity out, or pay the contractors a fixed price to produce the documentation, or have the documentation done in-house and pay the document producers a fixed wage.

H1B: When the quality of documentation cannot be measured accurately, and the producers of the code are also producing the documentation, they are likely to be paid a fixed salary.

In low-end organizations, often the task of documenting traceability is contracted out. Often these contractors are hired towards the end of the project to create documentation about how various artifacts produced during the development process are linked to each other. There is no doubt that the quality of this documentation is highly suspect as it is seldom possible for someone not involved in the development process to have the extensive knowledge required to create such linkages. High-end organizations, in contrast, rely on personnel involved in the development effort create traceability documentation as well. This, obviously, leads to high quality traceability documents in these organizations. In 
contrast, when low-end organizations use people who where not involved in the development process create traceability documents, their utility is severely limited. This seemingly irrational behavior by low-end organizations is explained by their interest in seeking arrangements for fixed compensation for the task. As these organizations have difficulty measuring the quality of the traceability documentation, they tend to rely on outsourcing.

\section{H2: $\quad$ A greater share of the evaluation of the employees charged with requirements traceability would be based on peer-evaluation.}

High-end organizations are very aware of the role of proper education on the role and usefulness of traceability across the development and maintenance life cycle. They use project meetings and peer reviews to highlight the importance of traceability efforts made by various individuals and their contribution to the success of the entire project. In such meetings they bring together the potential "producers" (e.g., designer) and "consumers" (e.g., implementers) of traceability information, thereby providing a forum for obtaining feedback on the quality of the output produced. Formal mechanisms such as peer reviews are used to provide valuable feedback to individuals. These peer reviews provide valuable feedback to the producers of traceability information about the quality of their development effort and identifies areas for improvement. This mechanism is often seen as an important mechanism for training and professional growth by the developers.

Low-end organizations, on the other hand, do not have effective means for evaluating the usefulness of the traceability information produced by their 'traceability' teams. They often are merely concerned with satisfying the sponsor's requirements for the existence of these documents rather than their quality. Therefore, they rely on more 'quantitative' measures of task success, which do not require expert evaluation and 'user' feedback.

H3: $\quad$ More resources would be invested in defining requirements precisely and identifying accountability.

Low-end users create traceability information only because the sponsors mandate it. They typically do not employ any formal methodology for their traceability practice and do not use sophisticated traceability tools. As discussed earlier, many low-end users even hire outside contractors to produce traceability documentation required by the project sponsor. The requirements for traceability are seldom clearly specified, beyond the 'deliverables' that satisfy the requirements of the project sponsor. This behavior can only be sustained if the sponsoring organizations are also fully educated about the consequences of creating such poor quality traceability documentation. If the sponsors realize that these documents seldom contain any useful traceability information they may force the low-end organizations to change their practices or at least avoid paying for such useless efforts.

Many high-end users realize that the absence of a well defined traceability scheme specifying what information needed to be captured by whom, and how it should be used, may lead to wide variations in the traceability information maintained by different project participants. For example, one organization in which we conducted a detailed case study of traceability practice, the project manager realized that the wide variations in the quality, quantity, and usefulness of design rationale and effort expended in capturing this information resulted from the absence of clear guidelines, both on the form as well as the content of traceability requirements. The project, therefore, was ordered to create formal models identifying the various objects and relationships among them. Here, an Entity-Relationship-Attribute model supported by the CASE tool used in the project was created. Many organizations define templates of traceability reports, which implicitly specify such models. These organizations have developed clear directives in task descriptions to ensure that relevant traceability information is captured at the appropriate source.

An important use of traceability knowledge is the ability to determine who is accountable for various project outcomes (such as critical design decisions). Gotel [16] proposes the use of contribution structure to highlight the importance of using a rich system of stakeholder roles in identifying the origins of requirements. Yu and Mylopolous [38] use dependencies between stakeholders as an important factor in the development of requirements.

Low-end users traceability practices focus mostly on relating requirements to various 'deliverables (such as system components) and compliance verification procedures (e.g., tests). They do not include detailed account of the 
process by which the outputs get developed and the roles of various stakeholders involved in the development process. Therefore, the use of traceability for determining accountability is very limited in these organizations. The traceability information contained in these projects is focused on linking different products produced during the development process, rather than the people or stakeholders involved in creating them. As a result in these organizations, access to tacit knowledge held by the developers is restricted since it is difficult to identify the relevant participants in the development process.

High end users, on the other hand, recognize that important elements of the development process should be clearly traced to their sources. One project manager observes "Accountability implies affordability." For example, a highend organization requires that each decision (and requirement) have an owner who is responsible for its justification and change. Such traceability helps minimize the proliferation of requirements and decisions that have little or unclear technical or functional justifications.

\section{H4: Employees would be evaluated on multiple measures of performance.}

High-end organizations recognize the need to provide both tangible and intangible rewards to encourage the capture of quality traceability information (e.g., providing adequate allowances in task schedules and costs for the "overhead" involved in capturing traceability information). The opportunity to learn from each other during the review process is considered an important intangible benefit by the employees. This helps them learn important skills from experienced developers and sharpen their skills necessary for career progression. Also, the opportunity to learn about other projects, methods and tools is also valued very highly in high end organizations.

High-end users also recognize the need to reduce disincentives to foster a climate conducive to a successful traceability practice. For example, they recognize that an important impediment to overcome is the fear among employees that the management may use traceability information improperly. While the employees would consider the use of traceability legitimately to communicate with the original designer of a system component, or to understand the capability of a system as legitimate uses, they consider the use of this information as a means for performance appraisal as inappropriate. Obviously, traceability knowledge should not be used to threaten employees. High-end organizations treat traceability information in ways similar to their use of information gathered during structured walkthroughs in systems development. Both are strictly used for understanding and improving the current system and not for performance evaluation. A technique employed by a high-end organization to minimize the risk of misuse is to have accountability for the critical elements (such as design decisions) assigned to an entire group after periodically providing the group with the opportunity to review the outputs of its members. This practice provides the benefit of peer review to individual employees while at the same time, relieving them of individual responsibility for 'mistakes' not discovered by their own peers.

H5: With increased traceability requirements, firms would be investing increasing resources on Quality Management (such as TQM) initiatives.

Many high-end organizations consider comprehensive traceability practice as an important component of their process improvement efforts. Several organizations reported that their traceability practice is essential to maintaining their process maturity levels and therefore, essential to their very survival. One organization we studied over a period of several months achieved Level 3 status (moving from Level 1) of the SEI CMM. They strongly believe that their comprehensive traceability practice (well beyond a narrow interpretation of requirements for traceability mentioned in CMM) was a critical factor in achieving this goal [32]. The ability to understand current practices by creating a history of the development process is an important diagnostic tool in process improvement.

H6: $\quad$ More of the employees charged with documenting traceability requirements would be "self-motivated" and less dependent on financial incentives as motivational devices.

In low-end organizations, the project participants do not see any financial or non-financial incentives that motivate them share process knowledge. Even individuals who maintain design notebooks that contain useful traceability knowledge use them as personal memory joggers to enhance their individual productivity rather than share it with others. 
High-end organizations create a climate that fosters knowledge sharing by a variety of means. These include providing employees access organizational memory of traceability knowledge (e.g., critical issues and design decisions) from similar projects, rewarding contribution to organizational memory, and recognizing individual contributions to process knowledge as an important element of project success. The professional recognition that is informally bestowed upon a designer for his/her contributions to the knowledge repository is considered a very powerful incentive.

H7: $\quad$ More resources would be invested in training employees about the importance of documenting traceability requirements.

High-end users take a "life cycle" view of costs and benefits to justify their comprehensive traceability practice. They realize that some critical benefits of implementing traceability (such as the savings resulting from the use of organizational memory of critical issues and decision rationale) will be realized across several projects. Similarly, some costs associated with implementing traceability practice are also treated as investments chargeable to several projects rather than the individual project during which it was incurred. This includes the cost of development of in-house traceability tools and utilities and the cost of training users in the CASE tools and methods.

Many high-end organizations recognize the need to educate their employees about the benefits of knowledge sharing among project team members provides many benefits. Bringing together the producers and users of traceability knowledge in project reviews and project meetings is one mechanism employed by these firms to facilitate such education.

H8: $\quad$ If outside contractors are employed, they would get the more easily measured tasks.

Only low-end organizations were observed to practice outsourcing of traceability tasks. They measure the outputs of these activities primarily using quantifiable measures such as the total number of reports produced, number of traceability matrices created etc. rather than on measures of quality that are much harder to establish.

Hypotheses 9-11 to follow are a direct consequence of what we know from the review of the accountability literature in Section 3.

H9: $\quad$ Organizations demanding greater accountability would see better quality process documentation of traceability requirements.

As the participants are expected to be accountable for their outputs, they are expected to develop more comprehensive process documentation. High end organizations where this expectation was common, develop much superior process documentation .

H10: Organizations demanding greater accountability would see greater consensus among team members on the contents of documenting requirements traceability.

As a mechanism for ensuring quality, high end organizations use peer reviews. This practice ensures that mistakes are identified early and corrective action is taken. Further, the team as a whole shares the responsibility for the products that have been subjected to peer review, tremendously reducing the anxiety individual developers may have about documenting their practices in detail.

\subsection{Conclusion}

Managerial incentives are among the critical factors that lead to the wide variations in traceability practice observed in our empirical studies. Our detailed examination of the literature on accountability and managerial incentives helps explain many apparently contradictory practices.

$\overline{A n}$ earlier version of this paper, entitled "On Managerial Incentives for Process Knowledge Capture and Use" appeared in The Proceedings of the 2001 Hawaii International Conference on Systems Sciences. 


\section{References}

1. S. Baiman, Agency research in managerial accounting: A survey, Journal of Accounting Literature, vol. 1, 1982, pp. 154213.

2. S. Baiman, Agency research in managerial accounting: A second look, Accounting, Organizations and Society, vol. 14 , no. 4, 1990, pp. 341-371.

3. S. Baiman and J.S. Demski., Economically optimal performance evaluation and control mechanisms, Journal of Accounting Research, vol. 18, 1980, pp. 184-220.

4. S. Baiman and J. Evans, Pre-decision information and participative management control systems, Journal of Accounting Research, vol. 21, 1983, pp. 371-395.

5. Banker, G.P. R., and D. Srinivasan, An empirical investigation of an incentive plan that includes nonfinancial performance measures, The Accounting Review, vol. 75, no. 1, 2000, pp. 65-92.

6. M. Bellandar, Workflow Bottlenecks and Problem areas influencing production management need in commercial printing, in Proceedings of Intergrafica, Zagreb, Croatia, 1997.

7. R.E. Bohn, Measuring and Managing Technological Knowledge, Sloan Management Review, vol. 36, no. Fall, 1994, pp. 61-73.

8. Davenport, Jarvenpaa, and Beers, Improving Knowledge Work Processes, Sloan Management Review, no. Summer, 1996, pp. 53-65.

9. T.H. Davenport, Process innovation : reengineering work through information technology, Boston: Harvard Business School Press, 1993.

10. P. Drucker, The Post capitalist Soceity, New York, NY: Harper Business press, 1993.

11. P. Drucker, Post Capitalist Society, First ed., New York, NY: Harper Business Press, 1993.

12. P. Drucker, Management Challenges for the 21st Century, New York: Harper Business, 1999.

13. R. Fielding, J. Whitehead, K. Anderson, and G. Bolcer, Web Based Development of Complex Information Products, Communications of the ACM, vol. 41, no. 8, 1998, pp. 84-92.

14. M. Gibbins and C. Emby, Evidence on the Nature of Professional Judgment in Public Accounting, in A.R. Abdel-Khalik and I. Solomon, ed., Auditing Research Symposium, Champaign, IL: Office of Accounting Research, University of Illinois at Urbana-Champaign, 1985.

15. R. Gibbons, Incentives in organizations, Journal of Economic Perspectives, vol. 12, no. Fall, 1998, pp. 115-132.

16. O. Gotel and A. Finkelstein, Contribution Structures, in Proceedings of Second International Symposium on requirements Engineering, York, U.K., 1995, IEEE Computer Society Press, pp. 100-107.

17. T. Hemmer, On the interrelationship between production technology, job design and incentives, Journal of Accounting and Economics, vol. 19, no. 2-3, 1995, pp. 209-245.

18. T. Hemmer, On the design of "modern" management accounting measures, Journal of Management Accounting Research, vol. 8, 1996, pp. 87-116.

19. V.B. Hoffman and J.M. Patton, Accountability, the Dilution Effect, and Conservatism in Auditors' Fraud Judgments, Journal of Accounting Research, vol. 35, no. 2, 1997, pp. 227-237.

20. B. Holmstrom, Moral hazard and observability, Bell Journal of Economics, vol. 10, no. Spring, 1979, pp. 74-91.

21. B. Holmstrom and P. Milgrom, Multi-task principal-agent analyses: Incentive contracts, asset ownership, and job design, Journal of Law, Economics and Organizations, vol. 7, 1991, pp. 24-52.

22. C. Ittner and D. Larcker, Total Quality Management and the choice of information and reward systems, Journal of Accounting Research, vol. 33, no. Supplement, 1995, pp. 1-34.

23. C. Ittner and D. Larcker, Quality strategy, strategic control systems, and organizational performance, Accounting, Organizations and Society, vol. 22, no. 3/4, 1997, pp. 293-314.

24. V.E. Johnson and S.E. Kaplan, Experimental Evidence on the Effects of Accountability on Auditor Judgments, Auditing: A Journal of Practice and Theory, vol. 10, no. Supplement, 1991, pp. 96-107.

25. J. Kennedy, Audit Judgment with Accountability: A Framework and Experimental Results, Journal of Accounting Research, vol. 31, no. 2, 1993, pp. 231-245.

26. J. Kennedy, D.N. Kleinmuntz, M.E. Peecher, and K. Hackenbrack, Determinants of the Justifiability of Performance in IllStructured Audit Tasks, Journal of Accounting Research, vol. 35, no. Supplement, 1997, pp. 105-130.

27. H. Mendelson and K. Kraemer, The Information Industries: Intorduction to the Special Issue, Information Systems Research, vol. 9, no. 4, 1998, pp. 1-4.

28. M. Meyer and M. Zack, The Design \& Development of Information Products, Sloan Management Review, vol. 37, no. 3, 1996, pp. 43-59.

29. M.E. Peecher, The Influence of Auditors' Justification Processes on their Decisions: A Cognitive Model and Experimental 
Evidence, Journal of Accounting Research, vol. 34, no. 1, 1996, pp. 125-140.

30. J.B. Quinn, P. Anderson, and S. Finkelstein, Managing Professional Intellect: Making the Most of the Best, Harvard Business Review, No. March-April, 1996, pp. 71-80.

31. B. Ramesh, Factors Influencing Requirements Traceability Practice, Communications of the ACM, vol. 41, no. 12, 1998, pp. 37-44.

32. B. Ramesh, C. Stubbs, T. Powers, and M. Edwards, Requirements Traceability - Theory and Practice, Annals of Software Engineering, vol. 3, 1997, pp. 397-415.

A. Robillard, The Role of Knowledge in Software Development, Communications of the ACM, vol. 42, no. 1, 1999, pp. 87-92.

B. Shapiro and H. Varian, Versioning: The Smart way to Sell Information, Harvard Business Review, no. November-December, 1998, pp. 16-114.

33. Tiwana and B. Ramesh, A Design Knowledge Management System to Support Collaborative Information Product Evolution, Decision Support Systems, vol. 31, 2001, pp. 241-262.

34. C.W. Turner, Accountability Demands and the Auditor's Evidence Search Strategy: The Influence of Reviewer Preferences and the Nature of the Response (Belief vs. Action), Journal of Accounting Research, vol. 39, no. 3, 2001, pp. 683-706.

35. K.P. Yglesias, Information Reuse Parallels Software Reuse, IBM Systems Journal, vol. 32, no. 4, 1993, pp. 615-620.

36. E. Yu and J. Mylopoulos, Understanding 'why' in Software Process Modeling, Analysis and Design, in Proceedings of 16th Intl. Conference on Software Engineering, 1994, pp. 159-168.

37. M. Zack, Electronic Publishing: A Product Architecture Perspective, Information \& Management, vol. 31, 1996, pp. 75-86.

\section{Notes}

